\title{
Efficiency of E-Learning Tools and Technologies to Progress Educational Eminence
}

\author{
S Jaya Prasanna , G. Sripradha, P. Kumaragurudasan
}

\begin{abstract}
The area of knowledge in the area of communication is growing at a significant rate and has reformed the usual patterns of teaching-learning processes. A variety of methodological tools have been established to provide the varying circumstances and difficulties of higher education learners. One of the significant technological innovations is that e-learning can be designated as the use of the Internet and computers to support teaching and learning, and many e-learning tools are currently accessible for use in education. E-learning tools can provide training and revision to a large number of students with varying social circumstances and information levels. This article discusses the concept of e-learning, its importance in education, its features and the categories and gadgets of e-learning
\end{abstract}

Keywords: Education, E-Learning, E-Learning tools, technical innovation.

\section{INTRODUCTION}

In this digital era, an innovative method of ascertaining in education called electronic-learning (e-learning) is familiarized. The electronic-learning diminutions the instructive expenses and it is further operative learning than conventional learning. Universally, the situation permits the reckless spreading of novel procedures and methods, withdrawing topographical contests. In accumulation, time effectiveness theaters a part, as transportable are reduced. Users can suitably entree tutoring resources from household or on the travel through the Internet.

A novice or undergraduate who is composing usage of current digital technology over internet is supposed to be obtaining information by electronic means or in other words the computers and internet are donating to learner knowledge. This, in communal phrasing, is termed as Electronic-learning. E-learning has not only turn out to be extensive in USA, Canada and Europe, it is fetching prevalent in India at the advanced tutoring level. E-leaning emphases on practice of knowledge in the arena of tutoring and education. E learning states the usage of innovative knowledge of information and communication technology (ICT) in the education procedure where the unconventional knowledge includes electronic media. E-Learning theatres a vibrant role in enlightening the eminence of education.

Revised Version Manuscript Received on 10, September 2019.

S Jaya Prasanna Ph.D Student, Jain college, Thoraipakkam, Chennai, Tamil Nadu, India.(Email: aashisrikrish@gmail.com)

G. Sripradha, Ph.D. Student State Resource Centre,Adyar Under Madras University, Chennai, Tamil Nadu, India.(Email: shripradha.sathish@gmail.com)

Dr P. Kumaragurudasan, Research Supervisor, State Resource Centre, Adyar Chennai, Tamil Nadu, India.(Email: kalaiselvirathna@gmail.com)

\section{ELECTRONIC-LEARNING}

E-learning or "electronic learning" is a canopy phrase that designates tutoring by means of electronic strategies and digital media. It incorporates all from outmoded tutorial room that integrates elementary knowledge to online academies.

The perception of e-learning nurtures in e-commerce, but it does not have a mutual explanation presently. In the beginning, e-learning emphases on learning grounded on the internet. But basically, the multimedia learning is comprised under eLearning. At the intellectual level, e-learning discusses to usage of electronic media in the arena of education, and in a further precise way, its pacts with education supported out by means of internet. Since e-learning is handler approachable and informal to intermingle, henceforth its practice is nowadays chosen at a universal level.

The rudimentary opinion of e-learning is the Erection Attitude Philosophy, which arose into reality after the arrival of network and multimedia. In the existing setting, knowledge fluctuate hastily, hence technical familiarity is not adequate enough to outfit the necessities of the varying periods.

Empathetic e-Learning is modest. e-learning is education employing automated skills to admittance instructive prospectus exterior of a traditional teaching space. In utmost belongings, it discusses to a progression, program or grade distributed totally online.

There are various standings used to define knowledge that is distributed online, via the internet, extending from Distance Education, to electronic learning, online learning, internet learning and several others. It is interactive in that you can also connect with your instructors, tutors or other pupils in your class. Occasionally it is carried live, where you can "electronically" raise your hand and intermingle in actual period and from time to time it is a sermon that has been reproduced. There is always an instructor or lecturer intermingling/communicating with you and categorizing your contribution, your projects and your exams. e-learning has been recognized as a fruitful technique of training and education is fetching a mode of lifespan for many people.

E-learning in an old-style situation may embrace informative flicks and demonstrations. This can afford undergraduates with subject that is more energetic and attractive. The content that is intended to be instructive and pleasurable can be worn to carry on students' devotion while offering information concerning a specific theme. 
While some school rooms include digital skill, A Classroom Performance System (CPS), for example, provide an entirely cardinal knowledge atmosphere. It comprises an overhead projector for exhibiting videotapes, web material and a cardinal board for the instructor. Students can involve themselves in contests and tests using cardinal response pads rather than doing in traditional method. The paperless situation affords a well-organized way for students to learn and ensures teachers always have the latest instructional resources.

Wired edification is added mutual form of e-learning. Many colleges and universities now permit student to present coursework and complete tests online. Some educational establishments are $100 \%$ wired, meaning undergraduates at no time have to be present inside a physical classroom. In order to preserve logic of community, online universities often provide and even require students to participate in online discussions through virtual learning environment.

Wired courses are characteristically directed by a qualified tutor who may give live or documented talks that students can watch online. The instructor also marks students' projects and is accessible to response specific queries. In maximum cases, recognitions received online are comparable to those received in outdated classroom scenery.

\section{III.IMPORTANCE OF E-LEARNING IN EDUCATION \& RESULTS}

The online culture is finest for all. This is a revolt in education field. The information can be accessed, communicated, captivated and shared everyplace. E-Learning has made edification calm for one and all including office-goers, housewives etc. without negotiating much. The following points emphasis the importance of e-learning in education

- $\quad$ E-Learning is operative and authoritative. It brands the information easy to clasp and engross. It conveys boosted skill to study and contrivance among the students. The Audio-Visuals help in retention of the knowledge acquired through eLearning for an extensive period.

- $\quad$ E-Learning retains the learner's efficiency with the present tendencies.

- $\quad$ Traditional classrooms, have ill-behaved rudiments to interrupt the class. Whereas, eLearning offers prompt distribution of instructions. It is a rapid method of education.

- $\quad$ Speeches can be reserved at any period and any numeral of times. In traditional classes, reviews are not that easy. if you have missed any lesson, you can at all times have it online.

- $\quad$ E-Learning allows trainers an advanced degree of exposure to deliver the content regularly. This guarantees steadiness in learning.

- $\quad$ E-Learning is cost-effective as this technique rapid and relaxed. Long training period, organization structure, stationary, travel expenditure etc. is reduced.

- It is a supporter to those who feel anxious and detached in assemblies. It aids to learn without having to give up the luxuries of the atmosphere that the learners are comfort with.

- E-Learning has been a precious care for students around the universe. Previously the admittance to knowledge was not reachable to all. Pupils with financial restrictions, topographical limitations or bodily infirmities had rare openings in the speculative area. The same now hold admission to constant edification.

But with an effort to brand internet more reasonable and far accomplishment, it is probable to bond the slit between low-slung revenue communal and tech admittance to disperse the dilemma of commercial rift. E-learning with its escalating stimulus in the educational cluster will open gateways to unknown trails giving rise to new lead-ins.

\section{IV.TYPES OF ELECTRONIC-LEARNING}

Primarily, there are two types of E-Learning, they are

A. Synchronous E-Learning

B. Asynchronous E-Learning

\section{A. Synchronous E-Learning}

Synchronous, means "at the identical time," it includes collaboration of members with a trainer via the internet in real time. For instance - VCRs or Virtual class rooms that are nothing else but real tutorial room online. Members intermingle with each other and tutors through immediate messaging, chat, audio and video conferencing etc.and all the tutorial instructions can be documented and recorded for future reference. Its benefits are:

- Capability to record or trail learning events.

- Unremitting intensive care and amendment is probable

- Potentials of universal connectivity and association prospects among learners.

- Facility to brand the training for each learner.

\section{B. Asynchronous E-Learning}

Asynchronous material is "not synchronous", which allows learners to extend their learning at their convenient time, without direct contact with the practitioner. Basically, this means invoices data available 24/7. The advantage is that this kind of e-learning provides the learners with the information they need around the clock. It also has interface with other learners through message boards, bulletin boards and discussion forums. . Its advantages are:

- Accessible 'fair in time' for prompt knowledge and citation.

- Elasticity of approach from anyplace at any time.

- Skill to instantaneously reach a boundless number of learners.

- Consistency of substance and onetime charge of creation.

A new learning system called interdisciplinary learning is emerging. As the name suggests it is a combination of asynchronous and asynchronous learning approaches. This learning format uses online tutorials through virtual classrooms, and providing CDs, study material, and audio and visuals for self-study is now preferred over more than any other training. 


\section{ELECTRONIC -LEARNING TOOLS}

Ample amount of digitalized training tools has been designed with the perseverance of giving self-reliance to the learner, clarifying the management of educational between teachers and learners. The most popular 12 tools used in E-learning are presented below.

\section{A. Edmodo}

Edmodo is a guide that connects mentors and beginners, and is transformed into a communal organization. In this, mentors can create activity support meetings, manage and deliver educational resources, assess student skills, and connect with parents. It has abundant clients who combine to make a studying system which is highly motivated, transformed, and connected to openings derived from expertise and the digital atmosphere.

\section{B. Socrative}

Created by an enthusiastic crowd of entrepreneurs and engineer educators. It is a scheme that lets instructors to develop course-related, informational competitions that learners can resolve using small gadgets. Trainers can see the effects of events and modify subsequent subjects and embrace them further.

\section{Projeqt}

This tool helps you to do interactive program demonstrations, which can be used to map maps, links, online tests and videos that collaborate with active slides. During a class meeting, teachers can alter the visualization of various devices with students' speculative activities.

\section{Thinglink}

Thinglink agrees to generate collaborating images with harmony, vibration, scripts and photos. This tool bids the opportunity for instructors to engage in knowledge sharing practices which stimulate students' inquiry into interactive resources that teachers can use to enhance their knowledge.

\section{E. TED-Ed}

TED-Ed allows teachers, students, animators and educators to create educational lessons with a team of individuals who aspire to maximize skill and virtuous concepts. It permits teachers and students to democratize access to knowledge. With this tool, individuals can actively contribute to the cramming curriculum of others.

\section{F. $c K-12$}

This tool continues to cut the price of educational books. To attain its neutrality, the site has an interface that permits the production and distribution of informative materials over the website. It can be reproduced with the essential journalistic protocols in each area.

ClassDojo is a tool for improving student performance. Teachers provide their students with an immediate response, which makes them happy with positive attitude points in the class and makes students more interested in the learning process. ClassDojo Provides actual notifications such as 'Very Well Don Robert!' and 'A +', for working procedures, cheering association, and enabling message

\section{G. ClassDojo}

collaboratively. Enacted material about student performance can be pooled with parentages and supervisors.

\section{H. eduClipper}

This tool allows instructors and students to distinguish between notes and instructional materials. eduClipper enables it to collect information found on the Internet and then to link it with partners of previously created groups, which propose the possibility of online educational content, advanced research practices, and a digital record of what students have accomplished. Progress. Similarly, it gives teachers the opportunity to design a virtual classroom with their students and to create an assortment where all efforts are made

\section{Storybird}

Storyboard objects to encourage writing and reading skills among students through storytelling. With this tool, authors can create an interactive and easy to use interactive creative book online. Structured stories can be applied to blogs, sent by email, and printed.

\section{J. Animoto}

It is a digital tool that enables first-time videos to be created in a quick time and on any mobile device, helping to advance enthusiastic students and educators. The interface used in this is user-friendly, allowing editors to create audiovisual content tailored to educational needs

\section{ADVANTAGES OF ELECTRONIC-LEARNING}

Electronic-learning is yet to develop in to huge scale way of training teachers in the educational arena. Once related with the traditional means of training teachers and learners, e-learning has the advantages shown below

\section{A. Low Cost}

E-learning is far-off inexpensive than traditional methods of teaching because of no usage of paper and pencil and with the condensed expenditure of instructor training. It can be accepted out at any place and at any time. It also protects a lot of time and the several constraints will not be restricted to the amount of the class and quantity of students.

\section{B. Flexible}

E-learning can be supported out wherever without severe time restrictions. It primes to a stretcher atmosphere for students.

\section{Personalization}

Unlike traditional teaching practices in e-learning the course content is not preferred by teacher or some association and can aid students to acquire their own obligation of knowledge.

\section{CONCLUSION AND REMARKS}

The present era is a period of digitalization. E-learning focuses on the extensive use of teaching training. E-learning has a myriad of rewards for traditional practices of learning 
and is considered superior. E-learning is the most appropriate way to get a degree in education. A lot of learners are attracted to an excellent, self-learning education to help students achieve their degree. This thesis measures the emergence of e-learning in today's educational scene and provides a wide variety of e-learning tools that are renowned to accommodate the needs and circumstances of the diverse nature of learners. There are many benefits of e-learning, such as connectivity, elasticity, and interactivity. However, one must be cautious in using these methodological tools so that students are not overwhelmed by the technology of these tools. One of the key points to be taken in the presentation is that current e-learning systems broadcast some security issue because precautions are not synchronized in the e-learning development procedure.

\section{REFERENCES}

1. Bascelli, D. (2005). "Making Work Real: Building Virtual Learning Communities". In P. Kommers\& G. Richards (Eds.), Proceedings of World Conference on Educational Multimedia, Hypermedia and Telecommunications (EDMEDIA) Montreal, Canada June 27.

2. Biggs John (2003). Teaching for Quality Learning at University, second edition. Berkshire, UK: The Society for Research into Higher Education \& Open University Press.

3. R.G. Cárdenas and E.M Sanchez. Security Challenges of Distributed e-Learning Systems. (2005) ISSADS, 538-544, Springer, Series Lecture Notes in Computer Science, 3563 , http://dblp.unitrier.de/db/conf/issads/issads2005.html\#Ca rdenasS05.

4. J. D. Kibble et al. "Effective use of course management systems to enhance student learning: Experimental Biology 2007”, Adv. Physiology Education, Vol. 31

5. Laurillard Diana (2006) "E-learning in Higher education" in (Paul Ashwin ed.) Changing Higher Education: The Development of Learning \& Teaching: London, RoutledgeFalmer

6. Marton, F. and Booth, S. A. (1997). Learning and Awareness. Hillsdale, NJ: Lawrence Erlbaum

7. N. Provos, D. McNamee, P. Mavrommatis, K. Wang and $\mathrm{N}$. Modadugu. The ghost in the browser analysis of web-based malware. In: HotBots'07: Proceedings of the RST conference on First Workshop on Hot Topics in Understanding Botnets, Berkeley, CA, USA, USENIX Association (2007).

8. J. Rosato, C. Dodds and S. Laughlin, "Usability of Course Management Systems by Students", Dept. Computer Information Systems/ Computer Science, College of Scholastica, Duluth

9. Sharpe, Rhona and Benfield, Greg (2005), "The Student Experience of E-learning in Higher Education" Brooke's eJournal of Learning and Teaching, 1 (3).

10. R.T Snodgrass, S.S Yao, C. Collberg, Tamper detection in audit logs. In: VLDB '04: Proceedings of the Thirtieth international conference on Very large data bases, VLDB Endowment (2004) 504-515.

11. Teaching and Educational Development Institute, University of Queensland, "Teaching Large Classes Project 2001", Report 2003.

12. J. D. Kibble et al. "Effective use of course management systems to enhance student learning: Experimental Biology 2007”, Adv. Physiology Education, Vol. 31

\section{AUTHORS PROFILE}

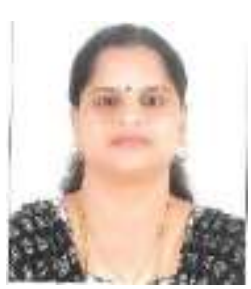

S Jaya Prasanna MCA., M.Phil.,

Doing Ph.D. in State resource Centre,Adyar under Madras University. Life Time member in Indian Science Congress. Gold Medalist. Published numerous papers in various journals and Attended numerous conferences, seminar and workshop Presently working as Asst professor in computer science department in DB Jain college, Thoraipakkam,

Chennai.Email: aashisrikrish@gmail.com

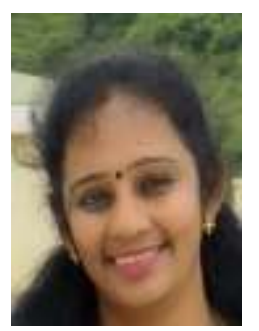

G Sripradha MCA, M.Phil.

Doing Ph.D. in State Resource Centre,Adyar Under Madras University.Freelance Trainer. Done Numerous Certification Programs and completedNumerous online cours Published numerous papers in various journals and attended numerous seminars, workshops and conferences

Email shripradha.sathish@gmail.com

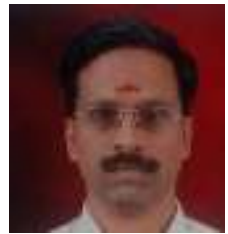

Dr P. Kumaragurudasan MA., Ph.D.Research SupervisorState Resource Centre, Adyar 20 Plus years of research experience

Published numerous papers in various journals and attended numerous seminars, workshops and conferences

Email_kalaiselvirathna@gmail.com 